\title{
A regulatory framework for an evolving electricity sector: Highlights of the MIT utility of the future study
}

\author{
IGNACIO J. PÉREZ-ARRIAGA, ${ }^{\mathrm{a}, \mathrm{b}, *}$ JESSE D. JENKINS,,${ }^{\mathrm{c}, \mathrm{d}}$ and CARLOS BATLLE ${ }^{\mathrm{a}, \mathrm{c}}$
}

\begin{abstract}
The electric power sector is once again evolving. A variety of distributed energy resources and improving computation, communication, and control technologies create an unprecedented degree of choice for electricity consumers, choices that are poorly guided by electricity rates and other incentives designed for a comparatively simpler era. These technologies also create new tools for regulated utilities, competitive suppliers, and other businesses to employ in the provision of electricity services. This paper summarizes the findings of a two-year, multidisciplinary MIT Energy Initiative research effort, the Utility of the Future study, and outlines a framework for proactive electricity regulation, market, and policy reform designed to enable the efficient evolution of the power sector over the next decade and beyond. Recommendations include a comprehensive system of efficient prices and charges for all electricity users, enbanced regulation of distribution utilities, careful reconsideration of industry structure to avoid conflicts of interest, and improvements to electricity markets. Together, this framework is intended to establish a level playing field for the provision and consumption of electricity services and enable the integration of a cost-effective combination of centralized generation, conventional network assets, and emerging distributed resources, whatever that mix may be.
\end{abstract}

Keywords: Regulatory Economics, Network Regulation, Electricity Rate Design, Electricity Market Design, Distributed Energy Resources

https://doi.org/10.5547/2160-5890.6.1.iper

\section{* 1. INTRODUCTION}

The electric power sector is once again evolving. For more than two decades, regulators and policy makers have been working to restructure and revise regulation of wholesale electricity markets, bulk power generation, and transmission networks to ensure efficient and reliable power supplies and achieve public policy goals. While this important work remains ongoing, attention must now shift to a confluence of factors in the distribution side of power systems.

A variety of distributed technologies - including flexible demand, distributed generation, energy storage, and advanced power electronics and control devices_-are creating new options

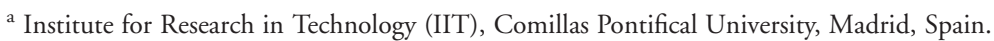

${ }^{\mathrm{b}}$ Center for Energy \& Environmental Policy Research, Sloan School of Management, Massachusetts Institute of Technology (MIT), Cambridge, MA, USA.

${ }^{c}$ MIT Energy Initiative, Massachusetts Institute of Technology (MIT), Cambridge, MA, USA.

${ }^{\mathrm{d}}$ Institute for Data, Systems \& Society, Massachusetts Institute of Technology (MIT), Cambridge, MA, USA.

* Corresponding author: ipa@mit.edu, +(34) 915406157.

Economics of Energy \& Environmental Policy, Vol. 6, No. 1. Copyright (C) 2017 by the IAEE. All rights reserved.
} 
for the provision and consumption of electricity services. At the same time, information and communication technologies are rapidly decreasing in cost and becoming ubiquitous, enabling more flexible and efficient consumption of electricity, improved visibility of network use, and enhanced control of power systems. These technologies create an unprecedented degree of choice for electricity consumers, choices that are poorly guided by electricity rates and other incentives designed for a comparatively simpler era. At the same time, these technologies create a new set of tools for regulated electric utilities, competitive suppliers, and other businesses to employ in the provision of electricity services. Electricity rate design, ${ }^{1}$ regulation of distribution utilities, industry structure, and wholesale market design must all adapt to these new realities.

For more than two years, an interdisciplinary team of researchers ${ }^{2}$ at the MIT Energy Initiative and the Institute for Technology Research (IIT) at Comillas Pontifical University has carefully studied the important changes now unfolding in the electricity sector. Our central conclusion: a set of proactive reforms to electricity regulation, policy, and market design are needed to enable the efficient evolution of the power sector over the next decade and beyond. While these reforms are discussed at greater length in the MIT Energy Initiative's Utility of the Future study (Pérez-Arriaga et al., 2016), ${ }^{3}$ we present here, in summary form, a regulatory framework for an evolving electricity sector. ${ }^{4}$ This regulatory framework consists of four parts.

The first part of the framework (Section 2) presents a comprehensive and efficient system of prices and regulated charges (e.g. rates or tariffs) for electricity services that reflect, as accurately as possible, the marginal or incremental cost of providing these services. Improved, cost-reflective prices and charges are essential to efficiently guide the myriad decisions made by electricity consumers, distributed resource providers, aggregators, and other businesses.

Second, we build on best practices from across North America and Europe to propose a set of improvements to the regulation of electricity distribution utilities that reward cost savings, performance improvements, and long-term innovation (Section 3).

Third, we carefully re-evaluate the structure of the electricity industry to minimize potential conflicts of interest (Section 4). This section builds on experience with restructuring of the bulk power system and adapts these insights to the distribution end of the power system. In particular, we focus on carefully assigning responsibility for the core functions of distribution system operation, network provision, market platforms, and data management.

The fourth and final section of this framework (Section 5) recommends a series of improvements to wholesale market design to better integrate distributed resources, reward greater flexibility, and minimize distortions from policy supports for various technologies.

Our goal here is not to predict the future, nor to promote (or hinder) the deployment of distributed resources. Rather, the framework proposed herein is designed to establish a level

1. A note to our international readers: in this paper, we employ the terms "electricity rates" and "rate design" more commonly used in the United States context and intend these terms to be synonymous with "electricity tariffs" and "tariff design" which are more common in European discussion. Indeed, the Utility of the Future report tends to employ the term "tariff," but we revise our convention here for the benefit of a North American audience.

2. Ignacio Pérez-Arriaga served as principal investigator for the MIT Energy Initiative Utility of the Future study with assistance from Christopher Knittel. Raanan Miller and Richard Tabors were project directors. The research team includes Ashwini Bharatkumar, Michael Birk, Scott Burger, José Pablo Chavez, Pablo Dueñas-Martinez, Ignacio Herrero, Sam Huntington, Jesse Jenkins, Max Luke, Raanan Miller, Pablo Rodilla, Richard Tabors, Karen Tapia-Ahumada, Claudio Vergara, and Nora Xu. This paper reflects their invaluable contributions to the Utility of the Future research effort.

3. The full Utility of the Future report is available at http://energy.mit.edu/uof.

4. Note that our research was focused on developed power systems in North America and Europe, but we consider a variety of regulatory contexts and aim to offer insights that may be of use in multiple jurisdictions. 
playing field for the provision and consumption of electricity services and enable the integration of a cost-effective combination of centralized generation, conventional network assets, and emerging distributed resources, whatever that mix may be. With this framework in place, all customers and producers of electricity services can make efficient choices informed by accurate incentives that reflect the economic value of these services, established public policy goals, and individuals' own diverse personal preferences.

\section{* 2. AN EFFICIENT SYSTEM OF PRICES AND CHARGES}

Users of electricity services today face an expanding array of choices. New businesses offer installation and financing of distributed generation, storage devices, and energy efficiency retrofits. Smart appliances and energy management systems are available to automate heating, cooling, lighting and other major electrical loads to save money and meet the consumer's personal preferences. Purchasing an air conditioner, refrigerator, light bulb or set of windows all affect the patterns of a household's or business's electricity use. Electric vehicles are becoming a more affordable option for many-and could become a significant new source of electricity demand.

Yet electricity users almost invariably face electricity rates and other incentives that offer them little guidance on how these myriad decisions affect the cost of electricity provision, not just for themselves, but for the power system as a whole. Large industrial customers have long faced a complex array of choices-from the design of industrial processes to the installation and operation of combined heat and power systems - and regulators thus established correspondingly complex rates that better reflect how these users' choices affect the time-varying cost of electricity production, the need for generation or network capacity, and even the impact on power quality and reactive power needs. Meanwhile, the vast majority of electricity users, including smaller industrial customers and nearly all commercial and residential users, face comparatively simple rates that reflect limited (if any) information about how the marginal cost of electricity services varies across both time and location. ${ }^{5}$ These rates also typically bundle costs associated with all of the electricity services that customers receive along with various public policy costs into a single rate in a non-transparent manner.

Simplified rates, including flat tariffs that allocate most costs in a volumetric manner, were workable in an era when the choices facing electricity consumers were simpler, and when the costs of the electricity system as a whole were driven primarily by the decisions of regulated utilities or large power producers. Acknowledging the importance of electricity rates that serve as efficient signals for distributed decision-makers is not new (see e.g. Bonbright, 1961; Schweppe, 1978; Schweppe et al., 1988). There have always been benefits to efficient rate design, since such rates result in more efficient response of demand. Yet in the past, the potential economic gains were comparatively modest, and regulators frequently balanced efficiency with other imperatives and objectives, including simplicity, equity, and price stability. At the same time, until recently, the cost of interval meters or "advanced meters" capable of recording with sufficient detail the electricity usage of individual customers was considered prohibitive for smaller consumers.

Today, however, the growing integration of distributed resources and the increasing affordability of devices enabling more flexible electricity consumption and more accurate me-

5. As of 2012, $98 \%$ of residential customers in the United States were on flat or inclining block rates (Cappers et al., 2016; FERC, 2012). 
tering magnifies the importance of well-designed economic signals and the ramifications of poorly designed rates, as discussed further by Green and Staffell (2017), Schill et al. (2017), and MacGill and Smith (2017) also in this issue (see also Bollinger and Hartmann, 2015; Borenstein, 2015; Cappers et al., 2016; Faruqui and Sergici, 2010). The proliferation of distributed energy resources and the increasing affordability of computing, communication, and control technologies means that the decisions made by myriad individual actors-businesses, households, electric vehicle owners-have a direct and growing impact on the cost of the power system as a whole (see e.g. Blonz, 2016; Castro and Callaway, 2017). While consumers may not yet be fully aware of these choices or their importance, and many distributed technologies and smart appliances remain niche products in some markets, the trend is clear: costs for solar phovoltaics (PV), fuel cells, energy storage, electric vehicles, and smart appliances are all falling (DOE, 2016; Lazard, 2016a, 2016b), hundreds of new businesses are rising to harness and market these resources to households, companies, and utilities (Burger and Luke, 2016), and competition between conventional and emerging options for the provision of electricity services is increasing. It is thus imperative to proactively improve electricity rate design to align the distributed decisions made by individuals and businesses with the efficient operation and planning of the power system and to create a level playing field for competition and coordination between centralized and distributed resources.

What is needed is a comprehensive and efficient system of economic signals-marketdetermined prices and regulated charges for electricity services-that reflect with sufficient accuracy the marginal or incremental cost of each electricity service and the variation in these costs across both time and location. Prices and regulated charges collectively determine, at each point of connection to the power system and each point in time, the economic value of the services provided or consumed by any particular network user. Incorrect economic signals can drive inefficient investment and operational decisions, enable costlier resources to displace more affordable ones, drive less efficient business models to crowd out more efficient ones, and result in more expensive electricity services for everyone and a corresponding loss of societal welfare. Building on the economics of electricity systems and detailed computational modeling of power systems, the Utility of the Future report recommends a variety of progressive improvements to electricity rate design. ${ }^{6}$

1. Ensure that all prices and charges are technology neutral and symmetrical. As electricity users become more responsive to prices and as distributed resources are more widely adopted, network utilization patterns will become increasingly diverse, undermining a central assumption behind most current rate designs: that large tranches of electricity customers can be lumped into homogenous classes and their effect on system costs averaged without significant loss in efficiency. Furthermore, defining specific rates for users employing specific devices would entail an untenable explosion of rates that reflect the widening array of distributed resources: a specific rate for solar owners or for storage owners, an EV owner rate, a smart thermostat owner rate, a solar and storage rate, a storage and $\mathrm{EV}$ owner rate, a rate for users with all of the above, etc.

Instead, rate design should acknowledge that an agent's impact on the power system depends only on the specific pattern of injection or withdrawal of power at a given time and location. Electricity rates should thus ideally be technology agnostic and based only on the injections and withdrawals of electric power at a given time, voltage level, and location in the

6. See Pérez-Arriaga et al. (2016), Chapter 4 for further elaboration. 
grid, rather than on the specific devices behind the meter. In addition, cost-reflective prices and regulated charges should be symmetrical, with injection at aiven time and place compensated at the same rate that is charged for withdrawal at the same time and place. ${ }^{7}$

2. Progressively improve the granularity of price signals with respect to both time and location. ${ }^{8}$ The cost and value of electrical energy varies across both time and space, the combined product of changing demand, the marginal cost of available generation resources, and network constraints. The marginal cost of energy can differ by orders of magnitude throughout the year and across different locations in the power system. This variation in the marginal price of electrical energy is well captured by the theory of spot pricing of electricity or locational marginal prices (LMPs) (Schweppe et al., 1988) and has become the foundation for efficient price formation in wholesale electricity markets across much of the globe. The theoretically ideal price signal for electrical energy would be to extend locational marginal prices down through the distribution network to capture the time- and location-varying value of electricity at every connection point to the system, including prices for active and reactive power (Caramanis et al., 2016). Efficient ideal prices would also fully reflect the social cost of any environmental externalities associated with marginal electricity consumption, including climate change-related damages.

While the theory is clear, practical ratemaking must contend with the current difficulties of computing LMPs at all points in the distribution system, the costs of implementation, and the implications for the complexity and volatility of resulting prices. Fortunately, it is not necessary to extend time and location-variant pricing all the way to the toaster-that is, to every single distributed device at all connection points - to achieve a satisfactory level of efficiency. Figure 1 depicts a range of options that progressively improve granularity and efficiency of prices and charges. We recommend that regulators significantly improve the temporal and locational granularity of electricity rates, but in doing so, carefully balance efficiency gains with implementation costs and considerations to arrive at the appropriate level of granularity for each jurisdiction. As experience with more complex and granular rates develops, automation and aggregation reduce the burden of responding to time-varying rates, and the costs and performance of distributed resources and computation, communication, and control technologies improve, the appropriate balance of costs and benefits will likely shift steadily towards the efficient ideal over time.

3. Apply forward-looking peak-coincident network capacity charges and scarcity-coincident generation capacity charges. In an ideal world, perfectly efficient and highly granular locational marginal prices would capture both short-run marginal costs of electricity consumption or injection and generate "congestion rents" that in the long run would both precisely recover the efficient investment in network capacity and signal the impact of network users' decisions on the need for network expansion. In reality, LMPs capturing distribution network constraints are not yet employed anywhere in the world, and only imprecisely at the transmission

7. This recommendation contrasts with the increasingly common practice of compensating exports of power from distributed generation (or storage) located behind the meter differently (e.g. less) than consumption of electricity at the same location and time. This makes little economic sense and invites regulatory arbitrage and potentially costly efforts to avoid power export. See Green and Staffell (2017) in this issue for more. Instead, if a kilowatt-hour of electrical energy costs $X$ cents to deliver a specific time and place, producing a kilowatt-hour at that same time and place should be compensated at $X$ cents, just as consumption at that time and place is charged the same cost. The same symmetry should apply to peak-coincident charges for network capacity or generation capacity, as discussed in this section, or any other electricity service embodied in rates.

8. This recommendation to progressively improve granularity with respect to time and location applies to all electricity services, not only to energy. However, to avoid repetition, we only discuss here the granularity of charges for electrical energy. 


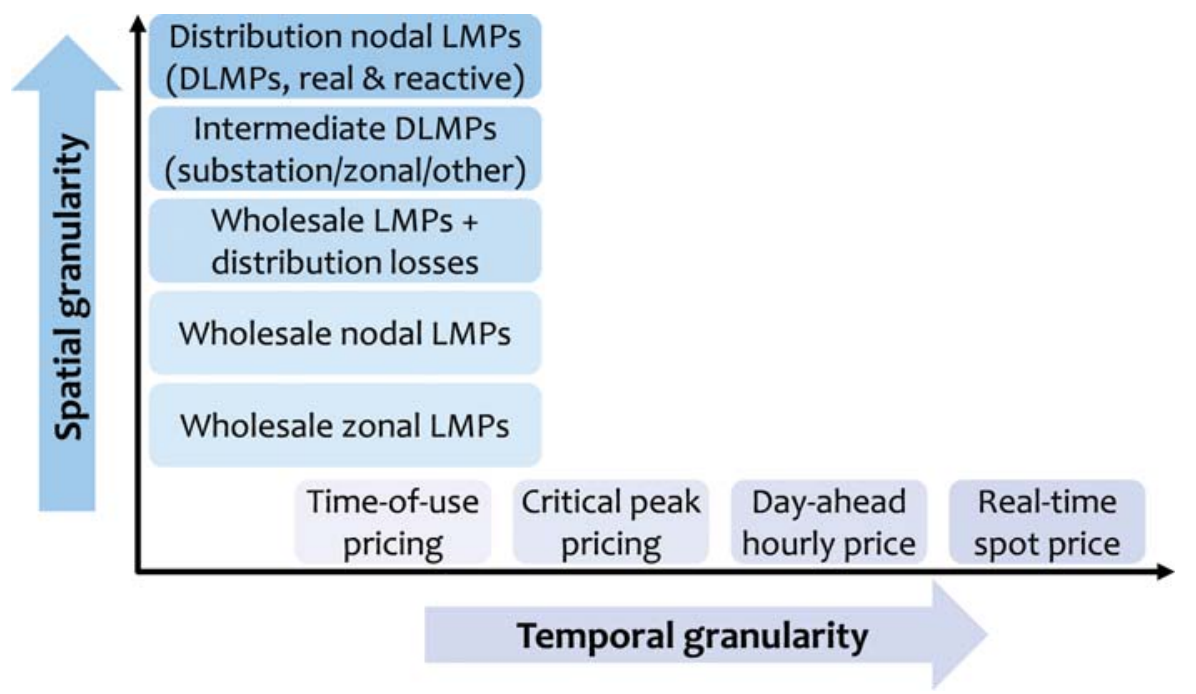

FIGURE 1

Options for progressively improving the temporal and spatial granularity of electrical energy prices.

Source: Own illustration.

level in many jurisdictions. ${ }^{9}$ Furthermore, even if distribution LMPs were widely adopted, the idealized circumstances needed for the above case to hold are never encountered in reality. ${ }^{10}$

In practice, additional, forward-looking price signals are needed to reflect the contribution of network users to the incremental future cost of transmission and distribution network expansion. ${ }^{11}$ As networks are expanded to accommodate peak capacity requirements under a range of plausible operating scenarios and anticipated system peaks (accounting for variations in season, weather patterns, load growth, and other factors), this signal could take the form of a peak-coincident network capacity charge reflecting how users contribute to the aggregate peak withdrawals of electricity in a given portion of the network. ${ }^{12}$ Furthermore, if distrib-

9. For example, European wholesale electricity markets employ zonal averaging of locational prices across wide regions, and even in the United States, where nodal LMPs are more commonly employed, demand is often settled based on a zonal average of LMPs.

10. That is, in the absence of economies of scale in network investment, of non-economically justifiable engineering design requirements, and of planning errors leading to excessive and irreversible investments, Rubio-Odériz (1999) proves that LMPs would completely recover the totality of efficiently incurred network costs. However, none of these assumptions holds true in reality. Moreover, risk aversion to power system failures can substantially magnify the impact of the other factors. In practice then, network rents generated by LMPs typically account for only a small percentage of total network cost recovery in transmission systems (Rubio-Odériz and Pérez-Arriaga, 2000), and would likely only contribute a fraction of distribution network costs under reasonable network planning and growth assumptions (Pérez-Arriaga et al., 2016, Chapter 4).

11. It is important to stress that, to improve efficiency, these prices should signal forward-looking or anticipated network expansion costs, not sunk or previously incurred costs that can no longer be avoided. This proposal is not intended as a method to allocate responsibility for previous network investment in a fair manner, but rather to improve the long-run efficiency of electricity systems by accurately signaling to network users how their behavior today contributes to or reduces necessary network capacity investments over time.

12. Note that these peak-coincident network charges contrast with commonly-employed customer "demand charges" which typically reflect a user's own individual peak consumption over a given period (e.g. a month). If a user's own peak consumption period occurs during off-peak periods when network capacity is not strained, it has little impact on the cost of network expansion (beyond perhaps the cost of the immediate connection point for that user). Such charges can result in significant economic distortions. 
uted generation penetration is significant enough that aggregate power injections drive network upgrades in some parts of the network, a charge for peak-coincident injections could also be levied in those areas. As with prices for electrical energy, this network capacity charge should be technology neutral and symmetrical — that is, any user that injects power during an aggregate peak withdrawal period or withdraws power during an aggregate injection peak by one kilowatt should be credited at the same value as a user is charged for contributing one kilowatt to that withdrawal or injection peak. A sufficient number of distinct system peaks throughout the year should be employed to allocate the capacity charges and ensure that variability in network use patterns is accounted for and randomness in the allocation of network charges is minimized. ${ }^{13}$ Since network capacity requirements are driven by localized peaks in withdrawal and injection, a sufficient degree of locational granularity is also required for peak-coincident capacity charges to deliver desired efficiency gains. As with energy prices, however, the appropriate degree of granularity must again balance potential efficiency gains with implementation costs.

However implemented, peak-coincident capacity charges that reflect a user's contribution to incremental network costs incurred to meet peak withdrawals and injections can play an important role in unlocking flexible demand and incentivizing distributed resources to be installed and operated at the right times and locations to avoid uneconomic network expansion and enable significant cost savings.

In addition, in most jurisdictions, the energy prices applicable to end-users and distributed resources are not fully reflective of marginal costs during periods of firm generation capacity scarcity (either due to wholesale price caps or simplified energy prices or the existence of some firm capacity remuneration mechanism). In such cases, it is also efficient for some additional signals to convey users' impacts on generation capacity costs, just as peak-coincident network charges convey their impact on network capacity requirements. For example, in the presence of a capacity market, a scarcity-coincident generation capacity charge can restore an efficient short-run incentive and determine the allocation of marginal generation capacity costs among users. This charge would reflect the coincidence of an end-user's consumption with the aggregate peak in the zone of the power system for which firm-generation capacity requirements are defined. These charges could be allocated to all hours when short-run wholesale prices rise above the marginal cost of the last committed generator, indicating scarcity in firm capacity. Distributed resources that inject power into the grid during aggregate peak periods should be credited with a symmetrical payment or bill credit reflecting the reduction in firm capacity requirements.

4. Allocate residual network and policy costs without distorting efficient incentives. Peakcoincident network charges and locational marginal prices for energy can both contribute to the recovery of network costs. However, it is likely that these price signals will not generate sufficient revenue to recover all regulated network costs, e.g. the regulated revenue requirements of network utilities (Borenstein, 2016; Rubio-Odériz and Pérez-Arriaga, 2000). Regulated network costs not recovered via cost-reflective prices and charges, which we refer to as "residual costs," should be recovered in a manner that does not distort or interfere with efficient short- and long-run price signals. In addition, electricity bills have often been a convenient tool used by policymakers to allocate costs derived from policy objectives such as energy efficiency, renewable energy subsidies, support to domestic fuels, low-income heating assis-

13. How many individual peaks is sufficient is an imprecise question, and warrants further study in specific contexts. More than ten but less than dozens is likely ideal. 


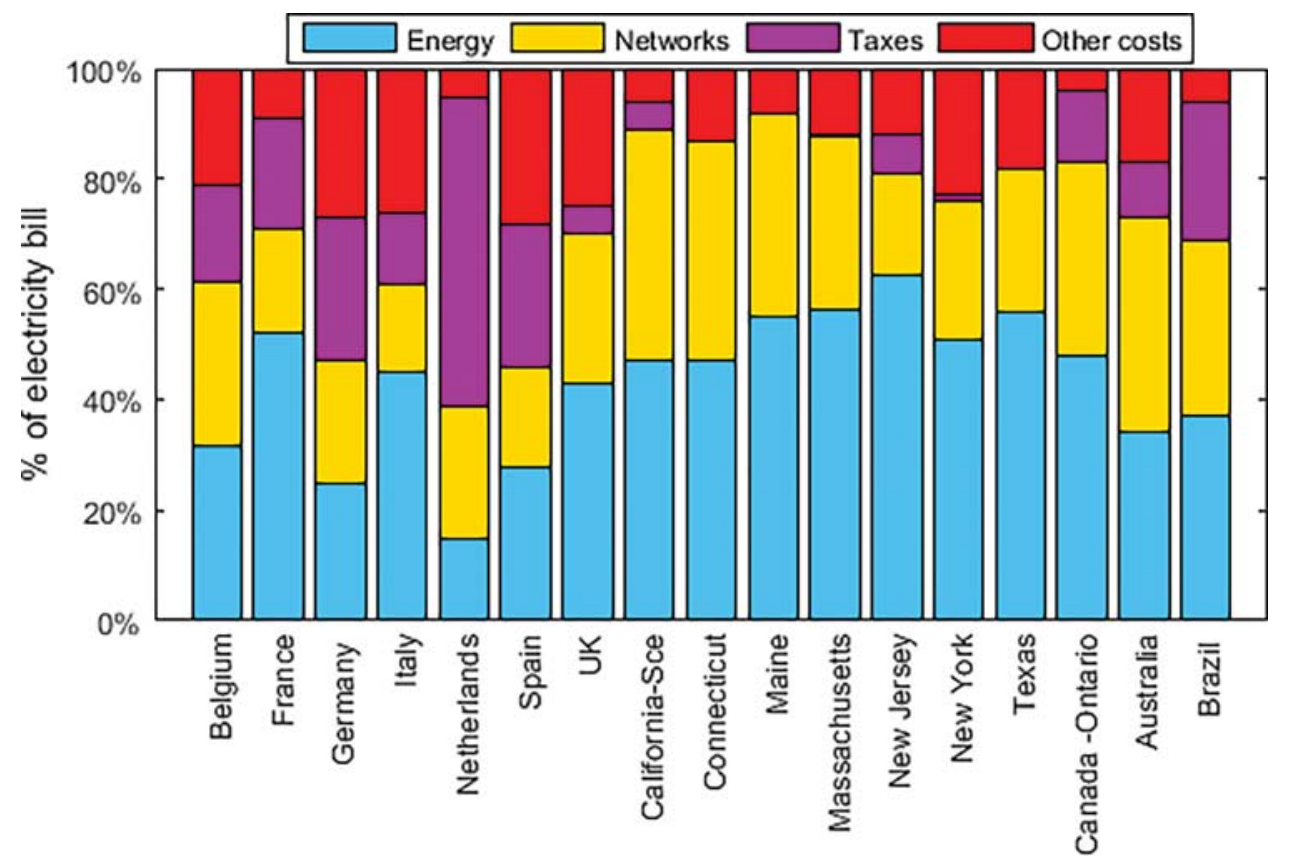

FIGURE 2

Components of residential electricity bills in different jurisdictions (2014-2015).

Source: Own illustration.

tance, climate change mitigation funding, or income redistribution. Taxes and other policyrelated costs represent a significant part of electricity bills in some jurisdictions (Figure 2). Any such costs not directly affected by changes in electricity consumption ${ }^{14}$ add to the amount of "residual costs" and must also be recovered in minimally distortive manner.

Recovering residual costs via volumetric charges (e.g. per kilowatt-hour) can result in significant distortions, because the signal modifies the price of energy at all times and all network nodes. Under such rates, individual users save money by reducing energy consumption or generating their own energy, but do nothing to modify total residual network or policy costs. ${ }^{15}$ This clearly either results in revenue shortfalls for critical public infrastructure and policy objectives or shifts these costs to other users. Individual agents likewise may invest their own resources or adjust their behavior in ways that appear privately beneficial but nevertheless result in a deadweight loss to society. ${ }^{16}$

14. Some policy costs are directly related to energy consumption, and thus should not be considered residual costs. For example, many jurisdictions have established renewable energy obligations or renewable portfolio standards policies that require utilities or retailers to produce or procure a percentage of their electricity from qualifying renewable sources by specified dates. In cases where changes in electricity consumption relate directly to the cost of public policies, such as renewable energy obligations that require a fixed share of electricity from renewable energy sources, it would be efficient to allocate some portion of these costs in a manner that reflects the impact of electricity use on the marginal cost of these policies. See Batlle (2011) and Batlle et al. (2016) for further discussion of cost-reflective and efficient allocation of these policy costs.

15. This distortion is further magnified under "net metering" policies that compensate power injections or exports from distributed generation by offsetting volumetric charges for consumption by the same network user during other time periods.

16. Note that if wholesale market prices or end-user energy rates do not fully reflect external costs associated with marginal electricity consumption, such as climate change-related damages due to $\mathrm{CO}_{2}$ emissions, then it may be efficient to increase volumetric energy charges to internalize some or all of these external costs. The revenues collected in this manner could then 
The alternative approach would be to recover policy costs via a fixed charge (e.g. a lump sum determined annually by the regulator for each customer and then charged, for instance, in equal monthly installments). In principal, this lump-sum payment would not distort shortterm efficient signals. How to allocate fixed charges in an equitable and acceptable manner remains an important regulatory consideration beyond the scope of this paper.

Furthermore, if residual costs can be avoided by disconnecting from the grid entirely, allocation of residual costs via fixed charges may spur so-called "grid defection" - an extreme form of long-run price elasticity in which network users self-supply all of their electricity services with distributed generation (and storage). While grid defection is uneconomic in almost all jurisdictions today, the declining cost of distributed resources may in time present an upper limit on the total sum of residual costs recovered via electricity rates (via fixed charges or otherwise). If network users defect en masse to avoid residual costs, it would be an even more extreme form of the distortion resulting from allocating these costs via volumetric charges. Regulators must therefore be wary of the implications of rate design for grid defection. Exit charges may be necessary to avoid significant cost shifting, and regulators and policymakers may ultimately wish to reconsider whether certain policy costs and even residual network costs are best collected via broader taxes, rather than electricity rates. ${ }^{17}$

\section{* 3. IMPROVED INCENTIVES FOR REGULATED DISTRIBUTION UTILITIES}

Establishing efficient incentives for electricity network users is critical to establish a level playing field for the cost-effective provision of electricity services by all resources. But it is not sufficient. Contemporary regulation of electricity distribution utilities is also ill adapted for the evolving landscape. Unless proactive reforms are made to update the regulation of distribution utilities, outdated network regulation may become a key barrier to the efficient evolution of power systems.

The proliferation of distributed resources creates new cost drivers and new network uses that contribute to greater uncertainty about the trajectory of distribution system costs. At the same time, these resources create new opportunities for utilities to make efficient trade-offs between capital investments in traditional network assets and novel operational expenditures, including contracts with or payments to distributed resources, flexible loads, or aggregators thereof that are capable of contributing to more efficient network operation. Dealing with these new uncertainties and challenges in an efficient manner will require utilities to become more innovative and pursue new opportunities to reduce costs and improve performance.

contribute to recovery of regulated network and policy costs, reducing the residual costs that must be allocated in a minimally distortive manner (this possibility is discussed in Borenstein, 2016). If electricity market prices and/or rates do not fully reflect external costs, other second-best measures may be welfare improving under such circumstances as well, including subsidies for clean energy or energy efficiency measures (see Jenkins and Karplus, 2016).

17. To be clear, we are not proposing to remove the short- or long-term economic signals (LMPs, in detailed or approximated form, peak-coincident network charges, and scarcity-coincident generation charges), which are necessary for efficient operation and investment, but only raise the question whether residual network costs should be included in electricity rates or not. In the same way that public schools are paid for by all taxpayers, regardless of whether or not they have children, and public libraries are supported by those who never use them, and most roads are paid by general taxes regardless of how much each taxpayer uses them, the existence of an electric network reaching to every building can be considered a necessary basic infrastructure in any developed society, and thus paid for via taxes and not specific electricity rates. Access to connection to the electric network is an added value or amenity for real estate, even if its owners decide not to connect to the grid and to self-supply electricity for their own needs. Full recovery of allowed regulated network costs is in the public interest. Whether these costs are recovered via electricity user rates or other means may be an open question in a future in which grid defection looms large. 
Powerful regulatory tools exist to manage these changes and establish appropriate incentives for distribution utilities. These regulatory tools can be divided into two categories: (1) improved approaches to distribution remuneration that can account for new cost drivers, new demands and uses of the distribution network, and increased uncertainty; and (2) additional incentive mechanisms for achieving specific outcomes that are not captured by improvements to the "core" remuneration process, including incentives for performance and quality of service improvements and long-term innovation. Our key recommendations for improved distribution utility regulation are summarized here. ${ }^{18}$

5. Reward utilities for cost-savings. Our first recommendation is to more closely align the business incentives of the distribution company with the continual pursuit of novel, costsaving solutions and ensure that the benefits of improved utility performance are shared between utility shareholders and ratepayers. The principal mechanism used to reward cost-saving efforts is the multi-year revenue trajectory with profit sharing. This mechanism is a key component of regulatory regimes that go by many names, including "revenue caps," "RPI-X," "multi-year rate plans," and others. In each case, the basic objective is the same: utilities should be assured that, over some defined period of time, their revenues will to some degree be decoupled from their costs, so that utilities will be able to retain a share of any cost savings they may achieve during that time period.

An essential characteristic is that such multi-year trajectories are set in advance with clear rules established ex ante for adjustment to exogenous uncertainties outside of the utility's control and provide sufficient regulatory certainty as to how any realized cost-savings will be shared between ratepayers and utility shareholders. These features are important to provide the regulatory certainty needed for utilities to confidently pursue cost-saving efforts. Establishing a credible multi-year revenue trajectory requires methods for forward-looking benchmarking of efficient utility costs, as both future demands for network services and available solutions will not look like the past (e.g. both the efficient frontier and demand for utility services will evolve; see Cossent, 2013).

When used in conjunction with multi-year revenue trajectories, profit-sharing (or earnings-sharing) mechanisms share profits from efficiency gains and distribute risks between utilities and ratepayers (Joskow, 2014; Lowry and Woolf, 2016; Malkin and Centollela, 2013). Under a profit-sharing mechanism, utilities retain only a portion of any reductions in cost below the revenue trajectory, with the remaining share accruing to ratepayers in the form of lower rates. Likewise, if actual expenditures exceed the revenue trajectory, utilities bear only a portion of the excess cost, with rates increasing to share the remainder of the burden with ratepayers. The profit-sharing mechanism thus preserves utility incentives for cost reduction (improved productive efficiency) but does not fully decouple allowed revenues from realized utility costs, thus improving rent extraction and allocative efficiency (if costs fall below the revenue cap) and mitigating utility exposure to uncertainty (if costs rise above the revenue cap).

Furthermore, the regulator can improve on a single profit-sharing factor by offering regulated utilities a menu of regulatory contracts with a continuum of different sharing factors (Crouch, 2006; Cossent and Gomez, 2013; Lafont and Tirole, 1993; Ofgem, 2013a). A menu of contracts allows the firm to play a role in selecting the strength of cost-saving incentives. If constructed correctly, this menu establishes "incentive compatibility" - that is, the menu

18. For additional discussion, see also Pérez-Arriaga et al. (2016), Chapter 4, as well as Luke (2016) and Jenkins and PérezArriaga (2017). 
ensures that a profit-maximizing utility will always be better off (i.e. earn the greatest profit and return on equity) when the firm accurately reveals its ex ante expectations of costs over the multi-year revenue period. Incentive compatibility thus eliminates incentives for firms to inflate their cost estimates while rewarding firms for revealing their true expected costs to the regulator. This helps minimize strategic behavior and information asymmetries.

6. Equalize incentives for efficiency in capital and operational expenditures. Utilities are facing increased trade-offs between investments in network assets and novel operational and network management strategies that harness distributed resources, flexible demand, or aggregations thereof. Equalizing incentives for efficiency across capital expenditures (CAPEX) and operational expenditures (OPEX) is a key step toward giving utilities the flexibility to incorporate novel means of providing network services.

Incentives are typically skewed by conventional regulatory approaches, which add approved capital expenditures directly to a utility's regulated asset base or rate base, while operational expenditures are expensed annually. Even if utilities are properly incentivized to pursue cost savings via a profit-sharing incentive, saving one dollar of CAPEX will reduce the utility's regulated asset base, thereby reducing the allowed return on equity and net profit for the utility's shareholders. Distribution companies will therefore be fundamentally disincentivized from trading CAPEX for OPEX, including contracting with distributed resources to defer network investments.

The UK Office of Gas and Electricity Markets (Ofgem) has developed a mechanism for equalizing these incentives, known as the total expenditure or "TOTEX-based" approach (Ofgem, 2009, 2013b). Alternative measures have been proposed by the New York Department of Public Service (NYDPS, 2016). Whatever mechanism is pursued, the policy objective is to ensure that utilities are free to find the most cost-effective combination of conventional investments and novel operational expenditures (including payments to distributed resources) to meet demand for network services at desired quality levels.

7. Implement measures to manage inherent uncertainty in utility remuneration and to reduce information asymmetry. Regulators should start to test and use newly available tools to confront current lack of experience in several areas, including estimating distribution costs under the strong presence of distributed resources, managing forecast errors in the estimation of relevant distribution network cost drivers when developing multi-year trajectories for remuneration, and addressing heightened information asymmetry between regulators and utilities. Several state-of-the-art regulatory tools, including incentive-compatible menus of contracts, tested and reliable engineering-based reference network models, and automatic adjustment factors, should be used to ensure continued cost-efficiency under uncertain future conditions and increased information asymmetry. These measures are discussed in detail in Jenkins and PérezArriaga (2017).

8. Create output-based incentives for performance and quality of service improvements. Additional measures are required to incentivize utilities to move toward critical objectives or outcomes that are unrelated to short-term economic efficiency but are nonetheless important. These include objectives related to commercial quality of service, continuity of electrical supply, voltage quality (which together comprise quality of service), and energy loss reduction (Fumagalli et al., 2007; Lowry and Woolf, 2016; Malkin and Centollela, 2013; Ofgem, 2010). These outcomes are frequently not incentivized by core remuneration frameworks, since achieving improved performance may entail increased investment and operating costs, which are discouraged by the incentives for cost-savings discussed above. Regulators should thus 
leverage outcome-based performance incentives to reward utilities for measureable improvements in quality of service or other specified objectives, such as enhanced resiliency, reduced distribution losses, and improved interconnection times.

9. Establish explicit incentives for long-term innovation. Increased uncertainty about the evolution of network needs, cost drivers, and cost-saving opportunities will intensify the need for distribution utilities to engage in ongoing, long-term innovation, including expanded investment in demonstration projects, as well as the need for technological learning from such projects and dissemination of that knowledge between network utilities (Luke, 2016; Malkin and Centolella, 2013; Ofgem, 2010, 2013a). The Utility of the Future report presents case studies of several novel approaches used by regulatory authorities in Europe and the United States to establish input-based incentives and competitive rewards for the promotion of longterm innovation in electricity distribution networks. ${ }^{19}$ These examples could provide guidance to regulators as they consider adopting incentives for innovation. The objective is for utilities to transform into consistent adopters and integrators of novel solutions to reduce costs to ratepayers and improve performance outcomes over time.

\section{* 4. RESTRUCTURING REVISITED}

The growth and future potential of a variety of distributed energy resources and more priceresponsive and flexible electricity demand has sparked a new wave of debate over the structure of the electric power sector, this time focused on the role of distribution network owners and operators as well as end consumers, retailers, aggregators, and other new business models (CEER, 2015a; CPUC, 2014; Corneli and Kihm, 2015; de Martini and Kristov, 2015; European Commission, 2009, 2010; Pérez-Arriaga et al., 2013; NYDPS, 2014, 2015a, 2015b). This new and complex situation has strong parallels to the introduction of competition and new actors at the bulk power system level during the last three decades in many countries (e.g. European Commission, 2003, 2009, 2010; FERC, 1996, 1999; Millán, 2006). Although debates over industry structure at the bulk power system level have not fully ended (and perhaps never will), decades of experience in restructuring have highlighted a number of necessary structural and regulatory practices that underpin healthy electricity markets and operations. The Utility of the Future study draws useful insights from this experience and offers recommendations adapted to the context of distribution systems, distributed resources, and retailing and aggregation activities. ${ }^{20}$ These recommendations are intended to minimize potential conflicts of interest (e.g. vertical foreclosure) and establish the structural foundation for an efficient, well-functioning electricity sector.

10. Carefully assign responsibility for three key functions: market platform, network provision and system operation. In electricity markets, the trading and provision of services occurs at three levels. First, producers and consumers of electricity (or their representatives) buy and sell energy from one another, often taking advantage of market platforms, such as power exchanges or centralized markets run by system operators. Second, a physical transmission and distribution network must be built and maintained to deliver energy from generators to consumers. Third, system operators need to plan network development, procure certain technical services from market agents, and coordinate the dispatch of these market agents and

19. See Pérez-Arriaga et al. (2016), Section 5.3.2.

20. See Pérez-Arriaga et al. (2016), Chapter 6 for further elaboration. 
network assets to reliably and efficiently operate electricity systems. Market platforms, network providers, and system operators thus perform three critical functions that sit at the center of all transactions in electricity markets.

Control of each of these core functions affords the opportunity to exercise some degree of vertical foreclosure that would negatively impact the ability of certain upstream suppliers to access downstream customers or vice versa. Properly assigning responsibilities for these three functions is thus critical to an efficient, well-functioning electricity sector and to establishing a level playing field for competitive provision of electricity services by traditional generators and network providers, and by new businesses that harness distributed resources.

11. Weigh benefits and drawbacks for several models for industry structure and select the structure appropriate to each jurisdictional context. After carefully considering parallels and differences with the bulk power system context, ${ }^{21}$ we present three potential models for assigning the core functions of market platform, system operation, and network provision to different actors, as well as variations of these models. Each of these models carries benefits and challenges, summarized in Table $1,{ }^{22}$ which must be carefully considered along with the specific regulatory context to select the most appropriate structure for each jurisdiction.

The first model consists of a distribution network owner and system operator (DNO/SO), which combines the functions of distribution network provider, distribution system operator, and market platform for distribution services ${ }^{23}$ within a single utility (Pérez-Arriaga et al., 2013; NYDPS, 2015a). This option parallels the TSOs that have emerged to manage the bulk power system in Europe and other jurisdictions. As with TSOs, the DNO/SO should be independent of competitive activities to ensure impartial planning and operation of distribution systems and impartial procurement of services.

As a second model, the role of the distribution system operator could mirror that of the independent system operators (ISOs) that have been established in the United States and elsewhere at the bulk system level. A new independent distribution system operator (IDSO) could have responsibility for planning and operating distribution systems across a given geographic region, but would not own network assets (Friedrichsen, 2015; Wellinghoff et al., 2015). Individual wire companies within the IDSO's territory, meanwhile, would not be required to unbundle from competitive market segments such as retailing, generation, or DER ownership or aggregation. In practice, this separation between system operation and network ownership and maintenance at the distribution level entails several practical challenges (summarized in Table 1) and may be less feasible than at the bulk power system level.

The final option is to incorporate all of the critical functions, including ownership of the distribution network, distribution system operation, and any markets for distribution system services, into a closely regulated, vertically integrated utility. ${ }^{24}$ This utility could also be responsible for retailing, generation, and/or transmission ownership and operation. A vertically in-

21. See Pérez-Arriaga et al. (2016), Section 6.2.3.

22. See Pérez-Arriaga et al. (2016), Section 6.2.4 for further elaboration.

23. The markets established by the $\mathrm{DNO} / \mathrm{SO}$ would be specifically for services used within the distribution system, as distinct from existing markets for ancillary services used in bulk power systems, which are already well established by bulk system operators. Note that it is possible to separate responsibility for market platform operation from the system operation, planning, and maintenance functions of the DNO/SO (we discuss a variation of this model in Pérez-Arriaga et al., 2016, Section 6.2.4). Indeed, dividing the market platform role from the system operator and network provider roles closely parallels the bulk power system structure common in Europe, where market platforms are managed by power exchanges and system operation and network provision is managed by transmission system operators (TSOs).

24. Note that this model is not compatible with current law in the European Union (European Commission, 2009, 2010). 
TABLE 1

Benefits and challenges of different industry structures.

\begin{tabular}{|c|c|c|c|}
\hline & $\begin{array}{c}\text { DISTRIBUTION } \\
\text { NETWORK OWNER/ } \\
\text { SYSTEM OPERATOR } \\
(\mathrm{DNO} / \mathrm{SO}) \\
\end{array}$ & $\begin{array}{c}\text { INDEPENDENT } \\
\text { DISTRIBUTION } \\
\text { SYSTEM OPERATOR } \\
\text { (IDSO) }\end{array}$ & $\begin{array}{c}\text { CLOSELY-REGULATED, } \\
\text { VERTICALLY- } \\
\text { INTEGRATED } \\
\text { DISTRIBUTION } \\
\text { UTILITY } \\
\end{array}$ \\
\hline Benefits & $\begin{array}{l}\text { Economies of scope from } \\
\text { combining distribution } \\
\text { market platform, system } \\
\text { operation, and network } \\
\text { provider functions. } \\
\text { Structural unbundling } \\
\text { minimizes incentives for } \\
\text { discriminatory behavior } \\
\text { and ensures DNO/SO } \\
\text { acts as neutral platform } \\
\text { for competitive market } \\
\text { activities. } \\
\text { As a second-best } \\
\text { alternative, functional } \\
\text { independence can be } \\
\text { approximated via legal } \\
\text { unbundling and } \\
\text { sufficient "Chinese } \\
\text { walls" between the } \\
\text { network company and } \\
\text { competitive affiliates. }\end{array}$ & $\begin{array}{l}\text { Independent system } \\
\text { operator acts as neutral } \\
\text { facilitator of markets } \\
\text { and distribution system } \\
\text { operation. } \\
\text { Does not require owners } \\
\text { of distribution network } \\
\text { assets to be unbundled } \\
\text { from competitive } \\
\text { affiliates. }\end{array}$ & $\begin{array}{l}\text { Captures economies of } \\
\text { scope between all three } \\
\text { distribution system } \\
\text { functions as well as bulk } \\
\text { system functions. }\end{array}$ \\
\hline Challenges & $\begin{array}{l}\text { Structural unbundling can } \\
\text { be difficult to } \\
\text { implement in practice. } \\
\text { Effective functional } \\
\text { independence can entail } \\
\text { significant regulatory } \\
\text { burden. }\end{array}$ & $\begin{array}{l}\text { Hypothetical construct, } \\
\text { untested in practice. } \\
\text { Loses economies of scope } \\
\text { between IDSO and } \\
\text { wires company } \\
\text { activities, which could } \\
\text { entail significant } \\
\text { transaction and } \\
\text { coordination costs - } \\
\text { e.g., between IDSO } \\
\text { planning and operation } \\
\text { and wires company } \\
\text { investment and } \\
\text { maintenance. }\end{array}$ & $\begin{array}{l}\text { Significant regulatory } \\
\text { burden. } \\
\text { Reduced opportunities for } \\
\text { competitive provision of } \\
\text { distributed energy } \\
\text { resource services. }\end{array}$ \\
\hline
\end{tabular}

tegrated utility would have to be subject to close regulation to minimize opportunities for vertical foreclosure, including requirements to procure network services through transparent and open auctions open to all parties. 
12. Establish sufficient independence between the distribution system operator and any agents that perform activities in competitive markets. The restructuring of wholesale electricity markets demonstrated that establishing a market platform alone is insufficient to ensure competitive electricity generation and supply. In practice, both the system operator and network provider functions can significantly affect the ability of market agents to buy or sell electricity services. Previous attempts at functional and legal unbundling in the bulk power system (i.e. among wholesale generators and transmission system operators; see e.g. European Commission, 2003; FERC, 1996) have generally proven insufficient at enabling effective competition and were eventually replaced by more stringent requirements for greater independence of system operation and planning from competitive activities (e.g. European Commission, 2009, 2010; FERC, 1999). Just as the independence of transmission networks and bulk system operators was foundational for competitive wholesale markets, the best solution from a competitive market perspective is a structural reform that establishes financial independence (e.g. ownership unbundling) between the distribution system operation and planning functions and any affiliates in competitive markets, including adjacent wholesale generation and ancillary services markets and competitive retail supply and distributed resource provision or aggregation within the distribution utility's service territory.

Between the two primary alternatives to achieve structural independence-namely, a combined $\mathrm{DNO} / \mathrm{SO}$ with financial independence from competitive affiliates and an independent distribution system operator (IDSO) — only the former has so far proven its practical viability at the distribution level. Furthermore, the DNO/SO construct captures the significant economies of scope between system operation and physical network provision.

That said, we note that diverse conditions exist in various jurisdictions, and the objective of making distribution system planning and operation independent must be considered alongside the industry restructuring implications of this strategy in every regulatory jurisdiction and power sector context. As a second-best alternative, various forms of legal and functional independence can be established. These structures will need to be complemented by transparent mechanisms (e.g., auctions or markets) for selecting services where distributed resources and centralized network services might compete to ensure that no conflicts of interest are exercised. Facilitating a level playing field between distributed energy resources and conventional approaches to generation and network services is likely to remain challenging if distribution network utilities are vertically integrated. In that case, significant regulatory oversight will be required.

13. Assign responsibility for a fourth, increasingly-important function: data management and access. Experience in retail markets in Europe and elsewhere has demonstrated that all market participants need equal and non-discriminatory access to a degree of customer information sufficient to facilitate a level playing field for competition (CEER, 2015b, 2016). Likewise, timely and non-discriminatory access to data on network conditions and operation and planning decisions, as well as information on network customers, could be important to facilitate competition among distributed resource service providers and aggregators (NYDPS, 2015a). A fourth core function may therefore join market operation, network provision, and system operation at the heart of electricity markets: that of data platform or data hub.

This data hub could be responsible for securely storing metered data on customer usage, telemetry data on network operation and constraints, and other relevant information; providing non-discriminatory access to this data to registered market participants; and facilitating end consumers' timely and useful access to data on their own use of electricity services. 
Economies of scope between metering, system operation, and data access argue for combining responsibility for the data hub or data management function with the distribution system operator function. This once again places the focus on ensuring the effective independence of distribution system operation. If the distribution system operator is independent of other competitive agents, it can act as a neutral manager of the data hub. To the degree the system operator is integrated with competitive market segments, the importance of the data hub responsibility argues for further enhancement of functional independence or the establishment of an independent data hub manager. Decisions about the governance of the data hub are thus strongly related to the other structural choices discussed above.

\section{* 5. UPDATING WHOLESALE ELECTRICITY MARKETS}

While a comprehensive system of prices and regulated charges for electricity services will play a central role in efficiently integrating distributed resources and flexible demand into power system operations and planning, wholesale electricity markets design should be improved to remove any unnecessary barriers that impede the full participation of all resources-including distributed resources—or distort their competitive performance. Market design improvements are also needed to acknowledge the value of flexibility and minimize distortions from specific technology support mechanisms, such as renewable energy subsidies.

14. Expand markets to the intraday timeframe to reward flexibility and accurate forecasting and enhance liquidity and transparency by using more centralized and discrete (rather than continuous) market mechanisms. The first key step toward improving wholesale market design is to create a more flexible short-term market sequence, adapted to the different planning horizons of all available resources and capable of producing intraday price signals that reflect the operation of the power system between day-ahead markets and the time of electricity delivery.

The sequence of short-term markets present in today's power systems was strongly influenced by the operational procedures of centralized generating plants prior to market liberalization. These procedures led, for example, to day-ahead unit commitment procedures common in most power systems. Today, the day-ahead time horizon is no longer adequate for key market functions given the presence of price-responsive demand, intermittent energy resources, and more constrained operation of thermal generators, among other trends. Therefore, price signals are also needed during the intraday timeframe.

In the current United States context, where ISOs manage wholesale markets, we argue for an alternative settlement system that produces intraday price signals (without necessarily implementing intraday markets, as in the European Union; see Herrero et al., 2016). ${ }^{25}$ These price signals are necessary to create incentives for efficiently forecasting and managing increasingly variable generation and demand patterns ${ }^{26}$ and should reach all agents in the market.

For European markets, where power exchanges already allow intraday trading, our recommendations focus on improving liquidity and market transparency. Minimizing information asymmetries and opportunities for the exertion of market power is necessary to allow smaller entrants to compete on a level playing field and for power systems to thereby obtain the most efficient use of all resources. European power markets currently present numerous

25. See Pérez-Arriaga et al. (2016), Section 7.2.1 for further elaboration.

26. For example, wind energy forecast errors have gradually decreased due to the exposure of these generators to imbalance prices in various markets (Herrero et al., 2016). 
instances where large market players have a significant advantage over smaller ones. We recommend concentrating market transactions in centralized market sessions (which increases liquidity and reveals market participants' information) instead of relying on bilateral arrangements (Neuhoff et al., 2016). Reducing or eliminating the use of bilateral mechanisms is more critical as markets approach real time and the number of market participants shrinks. Where intraday auctions exist, we find a sequence of discrete auctions facilitates greater liquidity and transparency than continuous trading.

Closer to real time, all resources should participate in balancing and real-time markets for the management of their energy imbalances. Most system operators allow large market players to self-manage their imbalances (netting positive and negative deviations of several power plants within the same portfolio) and settle only their net deviations in the balancing market. Liquidity and transparency in balancing markets would improve if this kind of aggregation were avoided.

15. Adapt auction rules to incorporate new operational constraints and new resources. At present, electricity market rules are designed for traditional resources and large generators that can manage large portfolios. As such, bidding formats are not suitable for some new technologies, such as energy storage and demand response. The design of new bidding formats will be a key element in allowing market agents to include information about their costs and operating constraints necessary for the efficient operation of electricity markets.

One approach to this challenge, employed in the European Union, is to continue increasing the complexity of existing bidding formats. The scalability of this solution is questionable, however. A better alternative is the approach employed by U.S. ISOs, in which customized bidding formats are created for each type of resource that capture well their various constraints. In ISO markets, where multi-part bidding formats are already in place, it will be necessary to design new bidding formats (or significantly enhance existing ones) to accommodate new resources.

Market clearing and pricing mechanisms will become more complex as refinements in bidding formats are introduced. An outstanding debate is whether discriminatory side payments (so-called "uplifts") should be used in addition to uniform market prices, and if so, how to allocate their cost (see e.g. FERC, 2014; O’Neill et al., 2016). Different approaches create significantly different price signals, which affect both the short- and long-term decisions of increasingly responsive market agents (Herrero et al., 2015). To avoid discrimination against demand resources, the allocation of side payments (when they cannot be avoided) should be incorporated in the market-clearing procedure in a way that ensures revenue sufficiency for all market agents (whether on the generation side or the demand side).

16. Align reserve markets with energy markets and new flexibility requirements and capabilities. An efficient definition and computation of prices for operating reserves is key to encourage efficient operational and investment decisions. Like wholesale bidding formats and unit commitment procedures, reserve products are currently tailored to the characteristics of conventional generating technologies. To harness all cost-effective resources in efficient reserve provision, it is important to remove unnecessary barriers in current product definitions (e.g. reduce minimum bid sizes and allow aggregation) and to create innovative reserve products that value different capabilities. The objective of creating new reserve products should be to provide value to the power system as a whole. New reserve products should accommodate the diversity of new technologies, rather than creating a new product for each individual new technology. 
The connection between energy and reserves to reflect scarcity situations is an essential component of market design to promote efficient operation and investment decisions (Soft, 2003; Hogan, 2013). In most markets, the quantity of required reserves is fixed, regardless of the cost of those reserves or the value of additional reserves to the system. Instead, these reserve requirements should reflect the changing value of reserves to the system (i.e., the reserve market price) and should be periodically reexamined. The connection between reserves and energy prices should either be enforced explicitly in energy auctions or at least be facilitated by closely aligning the timelines of reserves and energy markets. Properly defined reserve requirements and price formation are important to appropriately compensate more flexible and reliable resources.

17. Enable all resources to participate in long-term capacity markets. Efficient pricing of energy and reserves may still not encourage adequate levels of investment in firm capacity resources, in the eyes of policy makers or regulators. These regulators or policy makers may institute long-term markets to procure firm capacity resources. If this is the case, non-conventional technologies should be allowed to participate on the same terms as traditional resources.

Capacity mechanisms have a two-fold objective: to provide a long-term hedge for investors and to ensure security of supply for consumers. Demand response, energy storage, and intermittent renewable generation can contribute in various degrees to solving the security of supply problem and should therefore be eligible to compete to provide capacity services. The key challenge is to ensure that different resources compete on an equal footing. All resources, including distributed resources or aggregations thereof, should thus be subject to the same conditions as any other technology participating in the capacity mechanism. ${ }^{27}$

18. Support schemes for clean technologies should be designed to minimize the distortion of efficient prices and signals. Regulators and policy makers may want to explicitly incentivize the installation of certain resources - for example, renewable or low-carbon electricity generation. If this is the case, support mechanisms should be implemented in a manner that minimally distorts the efficient price signals received by electricity market participants. Support schemes that distort the marginal price of energy create many challenges, for instance, by distorting short-term prices and incentivizing inefficient operating and investment decisions, such as artificially induced negative prices or investment in suboptimal locations.

Two measures can improve on conventional approaches to support mechanisms for specific technologies. First, production- or output-based incentives (such as feed-in tariffs, feedin premiums, and production tax credits) that provide a payment per megawatt-hour of production should be transitioned to capacity-based incentives, which take the form of an annuity for a fixed period of time per unit of capacity installed. Basing subsidies on megawatts not megawatt-hours delinks support payments from operating and market decisions and thus avoids distorting incentives for efficient operation. Second, if the supported sector is sufficiently mature, administratively determined subsidy levels can be replaced by competitive price discovery methods, such as reverse auctions or tenders, to establish the requisite level of support needed to secure the desired capacity. Competitive price discovery incentivizes continual improvement in the price and performance of subsidized resources over time, rewards facilities for locating in sites with greater expected market value (which can thus bid a lower required

27. See Pérez-Arriaga et al. (2016), Section 7.3.1 for further discussion and recommendations for the design of capacity remuneration mechanisms. 
annuity in the auction), and minimizes the level of public subsidy required to achieve policy objectives. $^{28}$

\section{* 6. CONCLUSIONS}

This paper summarizes a set of recommendations for proactive regulatory, policy, and market reform designed to enable the efficient evolution of the power system over the next decade and beyond. The purpose of our recommendations is to enable all energy resources, whether distributed or centralized, to participate in the efficient provision of electricity services while achieving other public policy objectives. Together, these recommendations serve to establish a comprehensive system of prices and regulated charges to guide the distributed decisions of all network users and to remove inefficient barriers to the integration and competition of distributed resources and centralized resources alike. Those barriers include outdated regulation of distribution utilities, power sector structures that may impede fair competition, and shortcomings in electricity markets.

The task now facing those responsible for the reliable and cost-effective planning, regulation, and operation of future power systems appears daunting. We recognize that regulatory reform invariably proceeds gradually and incrementally, and each jurisdiction must contend with different contexts and priorities. However, we also caution that proactive reform is the only defense against being caught flat-footed by challenges that may seem minor today, but could become insurmountable tomorrow. We hope that the recommendation contained herein and discussed further in the MIT Utility of the Future study can offer guidance on the path forward for an evolving electricity sector.

\section{* ACKNOWLEDGMENTS $\mathscr{k}$}

This paper and its recommendations reflect the work of the entire Utility of the Future study team, including Ashwini Bharatkumar, Michael Birk, Scott Burger, José Pablo Chavez, Pablo Dueñas-Martinez, Ignacio Herrero, Sam Huntington, Max Luke, Raanan Miller, Pablo Rodilla, Richard Tabors, Karen Tapia-Ahumada, Claudio Vergara, and Nora Xu. This research was supported by a consortium of 23 diverse organizations from across the energy sector and complemented by a distinguished Advisory Committee and Faculty Committee. For a full list of Consortium members and Faculty and Advisory Committee members, see the MIT Utility of the Future report. This paper and the Utility of the Future report represent the opinions and views of the research team who are solely responsible for its content, including any errors. The Advisory Committee and the Study Consortium Members are not responsible for, and do not necessarily endorse, the findings and recommendations herein. This work is dedicated to the memory of our friend and colleague Stephen Connors.

28. For market agents accustomed to fixed price production subsidies, such as feed-in tariffs or net metering, a capacity-based annuity may leave them exposed to an undesirable level of market price and quantity risk. It is possible to hedge agents to some degree to these risks, if desired, by indexing the annuity to an average market price index (reducing price risk exposure) and/or to the performance of a "reference facility" of similar resource type, vintage, and location (reducing exposure quantity or performance risk). For further elaboration, see Pérez-Arriaga et al. (2016), Section 7.3.2 and Huntington et al. (2016). 


\section{References}

Batlle, Carlos (2011). "A Method for Allocating Renewable Energy Source Subsidies among Final Energy Consumers." Energy Policy 39(5): 2586-95. http://dx.doi.org/10.1016/j.enpol.2011.02.027

Batlle, Carlos, Jose Pablo Chaves-Avila, Pablo Rodilla, Paolo Mastropietro, Tomas Gomez, and Ignacio J. PérezArriaga (2016). Regulated and policy charges and electricity bills for a distributed future: efficient price signals for increasingly elastic end-users. Cambridge, MA, USA: MIT Energy Initiative Utility of the Future Working Paper, MITEI-WP-2016-09.

Blonz Joshua A. (2016). Making the Best of the Second-Best: Welfare Consequences of Time-Varying Electricity Prices. Working Paper 275. Berkeley, CA, USA: Energy Institute at Haas.

Bollinger, Bryan and Wesley R. Hartmann (2015). Welfare Effects of Home Automation Technology with Dynamic Pricing. Working paper draft.

Bonbright, James (1961). Principles of Public Utility Rates. New York, NY, USA: Columbia University Press.

Borenstein, Severin (2015). The Private Net Benefits of Residential Solar PV: The Role Of Electricity Tariffs, Tax Incentives And Rebates. NBER Working Paper 21342. Cambridge, MA, USA: National Bureau of Economic Research.

Borenstein, Severin (2016). The Economics of Fixed Cost Recovery by Utilities. Working Paper 272. Berkeley, CA, USA: Energy Institute at Haas.

Burger, Scott and Max Luke (2016). Business Models for Distributed Energy Resources. Cambridge, MA, USA: MIT Energy Initiative Utility of the Future Working Paper, MITEI-WP-2016-02.

Cappers, Peter C., Anna Spurlock, Annika Todd, Patrick Baylis, Meredith Fowlie, and Catherin Wolfram (2016). Time-of-Use as Default Rate for Residential Customers: Issues and Insights. Report LBNL-1005704. Berkeley, CA, USA: Lawrence Berkeley National Laboratory, Smart Grid Investment Grant Consumer Behavior Study Analysis.

Castro, Felipe A. and Duncan S. Callaway (2017). Utility Pricing in the Prosumer Era: An Empirical Analysis of Residential Electricity Pricing in California. Allied Social Sciences Association Annual Meeting, Chicago, IL, USA, January 7, 2017.

Caramanis, Michael, Elli Ntakou, William. W. Hogan, Aranay Chakrabortty, and Jens. Schoene (2016). “CoOptimization of Power and Reserves in Dynamic T\&D Power Markets with Nondispatchable Renewable Generation and Distributed Energy Resources.” Proceedings of the IEEE 104(4): 807-36. http://dx.doi.org/10.1109/ JPROC.2016.2520758.

CEER (2015a). The Future Role of DSOs: A CEER Conclusions Paper. Brussels, Belgium: Council of European Energy Regulators.

CEER (2015b). CEER Advice on Customer Data Management for Better Retail Market Functioning. Report C14RMF-68-03. Brussels, Belgium: Council of European Energy Regulators.

CEER (2016). CEER Benchmarking Report on Removing Barriers to Entry for Energy Suppliers in EU Retail Energy Markets. Report C15-RMF-70-03. Brussels, Belgium: Council of European Energy Regulators.

Crouch, Martin (2006). "Investment under RPI-X: Practical Experience with an Incentive Compatible Approach in the GB Electricity Distribution Sector.” Utilities Policy 14(4): 240-244. http://dx.doi.org/10.1016/ j.jup.2006.05.005.

Corneli, Steve and Steve Kihm (2015). Electric Industry Structure and Regulatory Responses in a High Distributed Energy Resources Future. Future Electric Regulation Report No. 1. Berkeley, CA: Lawrence Berkeley National Laboratory. https://doi.org/10.2172/1237497.

Cossent, Rafael (2013). Economic Regulation of Distribution System Operators and Its Adaptation to the Penetration of Distributed Energy Resources and Smart Grid Technologies. PhD thesis. Madrid, Spain: Universidad Pontificia Comillas.

Cossent, R. and T. Gómez (2013). "Implementing Incentive Compatible Menus of Contracts to Regulate Electricity Distribution Investments.” Utilities Policy 27: 28-38. http://dx.doi.org/10.1016/j.jup.2013.09.002.

CPUC (2014). Order Instituting Rulemaking Regarding Policies, Procedures and Rules for Development of Distribution Resources Plans Pursuant to Public Utilities Code Section 769. Sacramento, CA: State of California Public Utilities Commission.

De Martini, Paul and Lorenzo Kristov (2015). Distribution Systems in a High Distributed Energy Resources Future. Future Electric Utility Regulation Report No. 2. Berkeley, CA, USA: Lawrence Berkeley National Laboratory. https://doi.org/10.2172/1242415.

DOE (2016). Revolution. . .Now: The Future Arrives for Five Clean Energy Technologies. Washington, DC: U.S. Department of Energy. 
European Commission (2003). Directive 2003/54/EC Concerning Common Rules for the Internal Market in Electricity and Repealing Directive 96/92/EC. Brussels, Belgium: European Commission.

European Commission (2009). Directive 2009/72/EC Concerning Common Rules for the Internal Market in Electricity and Repealing Directive 2003/54/EC. Brussels, Belgium: European Commission.

European Commission (2010). Interpretative Note on Directive 2009/72/EC Concerning Common Rules for the Internal Market in Electricity and Directive 2009/73/ EC Concerning Common Rules for the Internal Market in Natural Gas: The Unbundling Regime. Commission Staff Working Paper. Brussels, Belgium: European Commission.

FERC (1996). Order No. 888, Final Rule. Promoting Wholesale Competition Through Open Access Nondiscriminatory Transmission Services by Public Utilities (Docket No. RM95-8-000). Washington DC, USA: US Federal Energy Regulatory Commission.

FERC (1999). Order No. 2000, Final Rule. Regulation Transmission Organizations (Docket No. RM99-20-000). Washington DC, USA: US Federal Energy Regulatory Commission.

FERC (2012). Assessment of Demand Response and Advanced Metering: Staff Report. Washington DC, USA: U.S. Federal Energy Regulatory Commission.

FERC (2014). Operator-Initiated Commitments in RTO and ISO Markets. Staff Analysis in Docket No. AD1414-000. Washington DC: US Federal Energy Regulatory Commission.

Faruqui, Ahmad and Sanem Sergici (2010). "Household response to dynamic pricing of electricity: a survey of 15 experiments.” Journal of Regulatory Economics 38: 193-225. http://dx.doi.org/10.1007/s11149-010-9127-y

Friedrichsen, Nele (2015). "Governing Smart Grids: The Case for an Independent System Operator." European Journal of Law and Economics 39(3): 553-572. First online July 2012. http://dx.doi.org/10.1007/s10657-0129345-0

Green, Richard and Iain Staffell. "Prosumage' and the British electricity market." Economics of Energy and Environmental Policy 6(1): 33-50. https://doi.org/10.5547/2160-5890.6.1.rgre.

Herrero, Ignacio, Pablo Rodilla, and Carlos Batlle (2015). "Electricity Market-Clearing Prices and Investment Incentives: The Role of Pricing Rules." Energy Economics 47: 42-51. http://dx.doi.org/10.1016/ j.eneco.2014.10.024

Herrero, Ignacio, Pablo Rodilla, and Carlos Batlle (2016). Enhancing Intraday Price Signals in U.S. ISO Markets for a Better Integration of Variable Energy Resources. Cambridge, MA, USA: MIT Energy Initiative Utility of the Future Working Paper MITEI-WP-2016-05.

Huntington, Sam C., Pablo Rodilla, and Carlos Batlle (2016). Revisiting Support Policies for RES-E Adulthood: Towards Market Compatible Schemes. Cambridge, MA, USA: MIT Utility of the Future Working Paper MITEIWP-2016-07.

Jenkins, Jesse D. and Valerie J. Karplus (2016). Carbon pricing under binding political constraints. Helsinki, Finland: UNU-WIDER Working Paper 2016/44.

Jenkins, Jesse D., and Ignacio J. Pérez-Arriaga (2017). "Improved Regulatory Approaches for the Remuneration of Electricity Distribution Utilities with High Penetrations of Distributed Energy Resources." The Energy Journal 38(3): 89-117.

Joskow, Paul L. (2014). Incentive Regulation in Theory and Practice: Electricity Distribution and Transmission Networks. In Nancy L. Rose, ed., Economic Regulation and Its Reform: What Have We Learned. Chicago, IL, USA: University of Chicago Press.

Laffont, Jean-Jacques, and Jean Tirole. (1993). A Theory of Incentives in Procurement and Regulation. Cambridge, MA, USA: MIT Press.

Lazard (2016a). Lazard's Levelized Cost of Energy Analysis, Version 10.0. Available at: https://www.lazard.com/ media/438038/levelized-cost-of-energy-v100.pdf

Lazard (2016b). Lazard's Levelized Cost of Storage Analysis, Version 2.0. Available at: https://www.lazard.com/ media/438042/lazard-levelized-cost-of-storage-v20.pdf

Lowry, Mark N. and Tim Woolf (2016). Performance-based Regulation in a High Distributed Energy Resource Future. Berkeley, CA, USA: Lawrence Berkeley National Laboratory, Future Electric Regulation Series Report No 3. LBNL-1004130.

Luke, Max (2016). Promoting Innovation in Electricity Distribution Networks: New Tools for Regulators and Planners. Masters Thesis. Cambridge, MA, USA: Massachusetts Institute of Technology.

MacGill, Iain and Robert Smith (2017). "Consumers or prosumers, customers or competitors? Australian perspectives on possible energy users of the future." Economics of Energy and Environmental Policy 6(1): 51-70. https://doi.org/10.5547/2160-5890.6.1.imac. 
Malkin, David and Paul A. Centolella (2013). Results-Based Regulation: A Modern Approach to Modernize the Grid. Atlanta, GA, USA: GE Digital Energy.

Millán, Jaime (2006). Entre el Estado y el Mercado. Tres décadas de reformas en el sector eléctrico de América Latina (in Spanish). Banco Interamericano de Desarrollo, 2006. ISBN: 1597820288.

Neuhoff, Karsten, Nolan Ritter, Aymen Salah-Abou-El-Enien, and Philippe Vassilopoulos (2016). Intraday Markets for Power: Discretizing the Continuous Trading? DIW Discussion Paper 1544, Berlin, Germany

NYDPS (2014). Case 14-M-0101 Proceeding on Motion of the Commission in Regard to Reforming the Energy Vision: DPS Staff Report and Proposal. Albany, NY, USA: State of New York Public Service Commission, Department of Public Service.

NYDPS (2015a). Order Adopting Regulatory Policy Framework and Implementation Plan. Case 14-M-0101: Reforming the Energy Vision. Albany, NY, USA: State of New York Public Service Commission, Department of Public Service.

NYDPS (2015b). Staff White Paper on Ratemaking and Utility Business Models. Albany, NY, USA: State of New York Public Service Commission, Department of Public Service.

NYDPS (2016). Order Adopting a Ratemaking and Utility Revenue Model Framework. Case 14-M-0101: Reforming the Energy Vision. Albany, NY, USA: State of New York Public Service Commission, Department of Public Service.

Ofgem (2009). Electricity Distribution Price Control Review Methodology and Initial Results Paper. London, UK: Office of Gas and Electricity Markets.

Ofgem (2013a). Strategy decision for the RIIO-ED1 electricity distribution price control: Outputs, incentives and innovation. London, UK: Office of Gas and Electricity Markets.

Ofgem (2013b). Strategy decision for the RIIO-EDI electricity distribution price control: Financial issues. London, UK: Office of Gas and Electricity Markets.

O’Neill, Richard, Anya Castillo, Brent Eldridge, Robin B. Hytowitz (2016). "Dual Pricing Algorithm in ISO Markets." IEEE Transactions on Power Systems PP(99): 1-1. http://dx.doi.org/10.1109/ TPWRS.2016.2614891.

Pérez-Arriaga, Ignacio J., Christopher Knittel, Raanan Miller, et al. (2016). Utility of the Future: An MIT Energy Initiative response to an industry in transition. Cambridge, MA, USA: MIT Energy Initiative, Massachusetts Institute of Technology. Available at: http://energy.mit.edu/uof

Pérez-Arriaga, Ignacio J., Sophia Ruester, Sebastian Schwenen, Carlos Batlle, and Jean-Michel Glachant (2013). From Distribution Networks to Smart Distribution Systems: Rethinking the Regulation of European Electricity DSOs. Florence, Italy: European University Institute, THINK Project, Topic 12. http://dx.doi.org/10.2870/78510

Rubio-Oderiz, Francisco J. (1999). Methodology of Transmission Network Cost Allocation under a Competitive Regulatory Framework. Doctoral dissertation (in Spanish). Madrid, Spain: Institute for Research in Technology, Universidad Pontificia Comillas de Madrid.

Rubio-Oderiz, Francisco J. and Ignacio J. Pérez-Arriaga (2000). "Marginal Pricing of Transmission Services: A Comparative Analysis of Network Cost Allocation Methods." IEEE Transactions on Power Systems 15 (1): 448 54. http://dx.doi.org/10.1109/59.852158

Schill, Wolf-Peter, Alexander Zerrahn, and Friedrich Kunz (2017). "Prosumage of solar electricity: Pros, cons, and the system perspective." Economics of Energy and Environmental Policy 6(1): 7-32. https://doi.org/10.5547/21605890.6.1.wsch.

Schweppe, Fred C. (1978). "Power Systems '2000': Hierarchical Control Strategies.” IEEE Spectrum 15(7): $42-$ 47. http://dx.doi.org/10.1109/MSPEC.1978.6367813.

Schweppe, Fred C., Michael C. Caramanis, Richard D. Tabors, and Roger E. Bohn (1988). Spot Pricing of Electricity. Dordrecht, Netherlands, and Norwell, MA, USA: Kluwer Academic Publishers. https://doi.org/10.1007/ 978-1-4613-1683-1.

Wellinghoff, Jon, James Tong, and Jenny Hu. (2015). The 51st State of Welhuton: Market Structures for a Smarter, More Efficient Grid. 51st State Initiative. Solar Electric Industry Association. Washington DC, USA. 